\title{
ESTUDO DA VARIAÇÃO DA RESISTÊNCIA EXTERNA EM CÉLULA COMBUSTÍVEL MICROBIANA
}

\author{
R. H. NÚÑ̃Z ${ }^{1}$, P. S. MORAES ${ }^{1}$, R. B. BASTOS ${ }^{1}$, C. OGRODOWSKI ${ }^{1}$ e F. B. SANTANA ${ }^{1}$ \\ ${ }^{1}$ Universidade Federal do Rio Grande, Faculdade de Engenharia Química \\ ro.hnunez@gmail.com
}

\begin{abstract}
RESUMO - A variação da resistência externa $\left(R_{\text {ext }}\right)$ consiste em uma maneira simples e prática para otimizar o desempenho de uma célula combustível microbiana (CCM), com a finalidade de proceder, se possível, com ações que busquem reduzir as resistências internas do sistema. Neste contexto foram avaliados os efeitos da $R_{\text {ext }}$ frente à máxima densidade de corrente elétrica específica, a máxima potência gerada e por fim identificar as resistências internas totais $\left(\mathrm{R}_{\text {int }}\right)$, resistência ôhmica $\left(\mathrm{R}_{\mathrm{ohm}}\right)$ e a resistência à transferência de carga $\left(\mathrm{R}_{\mathrm{ct}}\right)$. A máxima densidade de corrente específica foi atingida com uma $\mathrm{R}_{\text {ext }}$ de $47 \Omega$ $\left(425,01 \mathrm{~mA} / \mathrm{m}^{2}\right)$, já a potência máxima foi de $208,25 \mathrm{~mW} / \mathrm{m}^{2}$ com uma $\mathrm{R}_{\text {ext }}$ de 47 $\Omega$. A determinação das resistências $R_{\text {int }}, R_{o h m}$ e $R_{c t}$ foi realizada através da regressão polinomial de segundo grau sendo os menores valores encontrados de $35,02 \Omega(560 \Omega), 2,05 \Omega(1000 \Omega)$ e $40,91 \Omega(47 \Omega)$. Dessa forma conclui-se que a $R_{\text {ext }}$ influencia tanto nos parâmetros eletroquímicos quanto na densidade energética e potência máxima atingida.
\end{abstract}

\section{INTRODUÇÃO}

O desenvolvimento de novas tecnologias para geração de energia, visando o uso de fontes de energia renováveis e/ou sustentáveis e o aproveitamento eficiente dos combustíveis fósseis tem sido visto como uma alternativa promissora. Neste contexto, novas opções têm surgido principalmente no campo da bioenergia, em destaque as células combustíveis microbianas (CCM). O crescente interesse nesta tecnologia está apoiado em duas habilidades que vão ao encontro dos atuais anseios da sociedade: geração de energia em paralelo ao tratamento de efluentes (Teleken J. T., 2013).

Uma CCM opera de modo semelhante a uma célula combustível química, onde a eletricidade é proveniente de uma reação de oxirredução. Entretanto, a CCM emprega microorganismos como catalisadores da reação. A principal vantagem do dispositivo biológico comparado ao sistema convencional é a possibilidade de empregar diversos compostos como combustíveis, inclusive efluentes domésticos e/ou industriais (Logan et al., 2006).

Embora a CCM seja considerada uma tecnologia próspera, existem muitos parâmetros influentes que vem sendo estudados para o seu emprego comercial, priorizando intensificar a geração de corrente elétrica (Pant et al., 2010). Neste sentido, muitas pesquisas buscam o desenvolvimento e conhecimento de novos materiais para os eletrodos (Scott et al., 2008), 
avaliam as mudanças nas suas geometrias e nas condições operacionais (Ieropoulos et al. 2005; Jiang e Li, 2009), frente à eletroquímica, dinâmica bacteriana e seu metabolismo que por sua vez influenciam a geração de corrente elétrica (Logan e Regan, 2006).

Outro fator que pode ser otimizado para o melhor desempenho de uma CCM consiste na resistência externa $\left(\mathrm{R}_{\mathrm{ext}}\right)$. $A \mathrm{R}_{\mathrm{ext}}$ controla o fluxo de elétrons do ânodo para o cátodo, afetando o potencial (V) e a geração de corrente elétrica (I), influenciando também as comunidades presentes no biofilme, a metanogênese e a potência de saída (W) da CCM (Jumg e Regan, 2011; Yazdi et al. 2011; Lyon et al. 2010).

Neste contexto, o objetivo deste trabalho consistiu em avaliar a influência da $R_{\text {ext }}$ no desempenho eletroquímico de uma CCM, através de análises eletroquímicas.

\section{MATERIAIS E MÉTODOS}

\subsection{Inóculo e Meio de Cultivo}

O biorreator foi inoculado com $20 \mathrm{~mL}$ do subproduto de uma CCM operada por cerca de quatro meses, originariamente inoculada com sedimento marinho e $20 \mathrm{~mL}$ deste mesmo sedimento in natura, ambos retirados da Lagoa dos Patos do Porto do Rio Grande, RS.

$\mathrm{O}$ meio de cultivo empregado ao compartimento anódico, apresentava em sua composição $\mathrm{NaHCO}_{3}\left(2,5 \mathrm{~g} \mathrm{~L}^{-1}\right), \mathrm{CaCl}_{2} \cdot 2 \mathrm{H}_{2} \mathrm{O}\left(0,1 \mathrm{~g} \mathrm{~L}^{-1}\right), \mathrm{KCl}\left(0,1 \mathrm{~g} \mathrm{~L}^{-1}\right), \mathrm{NH}_{4} \mathrm{Cl}\left(1,5 \mathrm{~g} \mathrm{~L}^{-1}\right)$, $\mathrm{NaH}_{2} \mathrm{PO}_{4} \cdot \mathrm{H}_{2} \mathrm{O}\left(0,6 \mathrm{~g} \mathrm{~L}^{-1}\right), \mathrm{Na}_{2} \mathrm{HPO}_{4} \cdot 12 \mathrm{H}_{2} \mathrm{O}\left(1,87 \mathrm{~g} \mathrm{~L}^{-1}\right), \mathrm{NaCl}\left(0,1 \mathrm{~g} \mathrm{~L}^{-1}\right), \mathrm{MgCl}_{2} \cdot 6 \mathrm{H}_{2} \mathrm{O}(0,1$ $\left.\mathrm{g} \mathrm{L}^{-1}\right), \mathrm{MgSO}_{4} \cdot 7 \mathrm{H}_{2} \mathrm{O}\left(0,1 \mathrm{~g} \mathrm{~L}^{-1}\right), \mathrm{MnCl}_{2} \cdot 4 \mathrm{H}_{2} \mathrm{O}\left(0,005 \mathrm{~g} \mathrm{~L}^{-1}\right), \mathrm{Na}_{2} \mathrm{MoO}_{4} \cdot 2 \mathrm{H}_{2} \mathrm{O}\left(0,001 \mathrm{~g} \mathrm{~L}^{-1}\right)$, extrato de levedura $\left(0,05 \mathrm{~g} \mathrm{~L}^{-1}\right)$ e acetato de sódio $5 \mathrm{~g} \mathrm{~L}^{-1}$ como fonte de carbono. A alimentação foi realizada diariamente sendo adicionado a um tanque estoque localizado na lateral do reator $800 \mathrm{~mL}$ do referido meio de cultivo. No compartimento catódico seu volume foi preenchido com uma solução de ferricianeto de potássio $\left(\mathrm{K}_{3} \mathrm{Fe}(\mathrm{CN})_{6}\right) 50 \mathrm{mM}$, constituindo o aceptor final de elétrons.

\subsection{Sistemas Experimentais e Condições Operacionais}

O reator foi projetado com dois cilindros concêntricos, sendo o cilindro interno correspondente ao ânodo e o externo ao cátodo tendo $0,0177 \mathrm{~m}$ e $0,04 \mathrm{~m}$ de diâmetro respectivamente e uma altura total do leito de $0,2 \mathrm{~m}$. O compartimento anódico corresponde a uma área interna igual a $0,012 \mathrm{~m}^{2}$ e o compartimento catódico $4,65 \times 10^{-6} \mathrm{~m}^{2}$. Os compartimentos foram separados por uma membrana catiônica (CMI-7000S - Membranas International Inc.).

Uma tela de aço inox (304, 32 mesh, fio 0,25mm - TEGAPE) foi utilizada como coletor de corrente elétrica estando localizada no interior do ânodo e do cátodo. Esta tela envolvia a membrana internamente em suas duas extremidades, ocupando $50 \mathrm{~mm}$ da base superior e inferior do cilindro interno (ânodo), no cátodo a tela envolvia a membrana externamente ao longo de todo seu volume. Para compor o eletrodo da célula foram acrescidos ao ânodo $18 \mathrm{~g}$ de partículas de grafite com diâmetro entre 0,50 a 1,40mm, ocupando 37,5 \% do seu volume $\left(1,8454 \times 10^{-5} \mathrm{~m}^{3}\right)$. 
Os reatores foram operados com o auxílio de uma bomba peristáltica que recirculava o meio de cultivo na câmara anódica sob uma vazão de 9,2766 mL / min. A temperatura do sistema foi mantida a $35^{\circ} \mathrm{C}$ em câmara termostatizada (Eletrolab. EL 101/2). O monitoramento da atividade do íon hidrogênio $\left(\mathrm{H}^{+}\right)$, foi realizado diariamente após alimentação, utilizando um pHmetro (TEKNA, T -1000), sendo o pH mantido entre 6,5 a 7,5.

A CCM apresentava seus terminais (ânodo e cátodo) nas bases superior e inferior, sendo estes ligados em série à $\mathrm{R}_{\text {ext }}$ para aquisição do potencial da célula. As mesmas condições foram mantidas durante todo o experimento (20 dias) e a cada 5 dias a variável em estudo $\left(\mathrm{R}_{\text {ext }}\right)$ foi modificada, iniciando-se com uma $\mathrm{R}_{\text {ext }}$ de $1000 \Omega$, e sequencialmente de $560 \Omega, 100$ $\Omega$ e $47 \Omega$.

\subsection{Análises Químicas}

A voltagem da CCM foi monitorada por um microcontrolador Arduíno, responsável pela aquisição e registro dos dados obtidos a cada $2 \mathrm{~min}$. A potência foi determinada conforme a Equação 1, sendo E o potencial, I a corrente específica que foi determinada segundo a Lei de Ohm, Equação 2 (Liu et al., 2005).

$$
\begin{aligned}
& P=\left(\begin{array}{l}
E x I / A
\end{array}\right) \\
& I=\left(V / R_{\text {ext }}\right)
\end{aligned}
$$

A determinação das curvas de polarização foi realizada através da variação do potencial, em relação ao eletrodo de referência (ER), empregando se um potenciostato/ galvanostato (PALMSENS _ Palmensens3). O ER assim como o contra eletrodo (CE) consistiram o terminal catódico, já o eletrodo de trabalho (ET) o terminal anódico. Esta análise foi realizada para cada uma das condições de $\mathrm{R}_{\text {ext }}$ estudadas.

As análises de Espectroscopia de Impedância (EIS) para a determinação dos parâmetros eletroquímicos como resistência ôhmica $\left(R_{\text {ohm }}\right)$ e resistência a transferência de carga $\left(R_{c h}\right)$ foram realizadas aplicando se um potenciostato (PALMSENS _ Palmensens3). A faixa de frequência utilizada foi de $1 \mathrm{mHz}$ a $20 \mathrm{kHz}$. Para a aquisição destas resistências, foi realizada uma regressão não linear de segundo grau.

\section{RESULTADOS E DISCUSSÃO}

A Figura 1 apresenta o comportamento ao longo do tempo da densidade de corrente específica e da potência específica. Da mesma forma, Aelterman et al. (2008) demonstraram que a geração de corrente contínua e a geração de energia aumentam com a redução da $\mathrm{R}_{\text {ext }}$. 
Figura 1 - Acompanhamento da geração da densidade de corrente $\left(\mathrm{mA} / \mathrm{m}^{2}\right)$ e da potência $\left(\mathrm{mW} / \mathrm{m}^{2}\right)$ obtida frente as alterações de $\mathrm{R}_{\text {ext }}$.
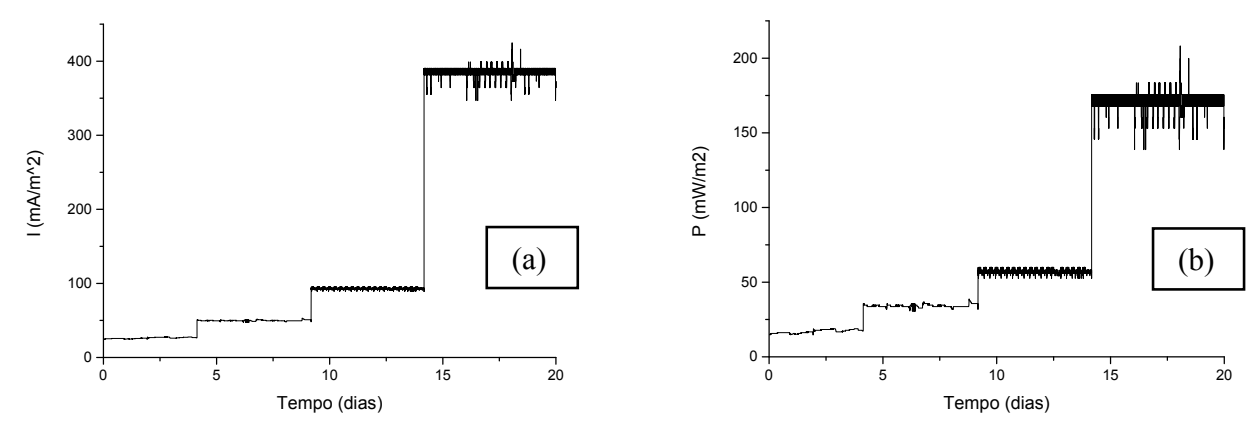

A Figura 1(a) ilustra o desempenho da densidade de corrente específica ao longo do tempo experimental e a Figura 1(b) corresponde à potência específica ao longo dos 20 dias de análise. Conforme a $R_{\text {ext }}$ foi reduzida a máxima corrente elétrica específica aumentou de $27,72 \mathrm{~mA} / \mathrm{m}^{2}(1 \mathrm{k} \Omega), 53,14 \mathrm{~mA} / \mathrm{m}^{2}(560 \Omega), 95,12 \mathrm{~mA} / \mathrm{m}^{2}(100 \Omega)$ até $425,01 \mathrm{~mA} / \mathrm{m}^{2}(47 \Omega)$, o mesmo ocorreu com o potencial máximo em cada uma das $\mathrm{R}_{\mathrm{ext}}$ em estudo apresentando valores de $18,85 \mathrm{~mW} / \mathrm{m}^{2}(1 \mathrm{k} \Omega), 36,70(560 \Omega), 114,51 \mathrm{~mW} / \mathrm{m}^{2}(100 \Omega)$ e $208,25 \mathrm{~mW} / \mathrm{m}^{2}(47$ $\Omega$ ). Segundo estudos realizados por Yazdi et al. (2011) quanto menor foi a resistência externa aplicada, maior foi a potência máxima alcançada para $20 \Omega$ obtiveram $66,00 \mathrm{~mW} / \mathrm{m}^{2}$ e 47,00 $\mathrm{mW} / \mathrm{m}^{2}$ referente a resistência de $1 \mathrm{k} \Omega$ ). As análises eletroquímicas (Curva de Polarização e Espectroscopia de Impedância) foram realizadas em $24 \mathrm{hs}$ antes da troca da $\mathrm{R}_{\mathrm{ext}}$, conforme ilustra a Figura 2.

Figura 2 - Análise da curva de polarização e espectroscopia de impedância.

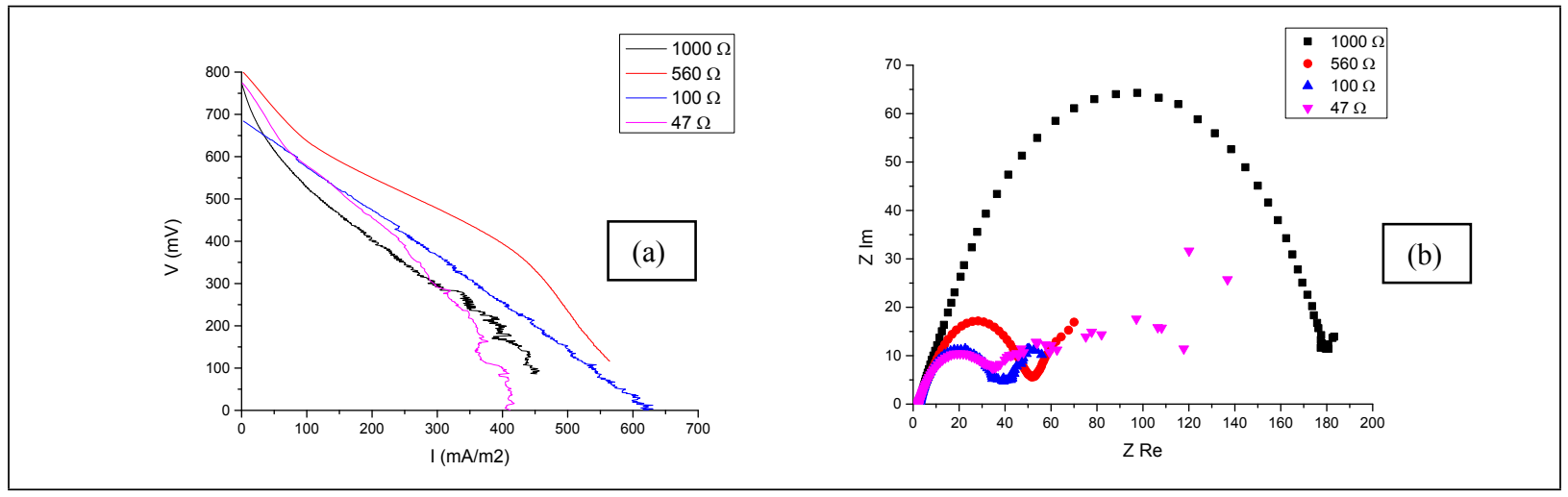

As curvas de polarização, Figura 2(a) ilustra o comportamento eletroquímico respectivo de cada variável em estudo. Conforme a redução da $\mathrm{R}_{\text {ext }}$ a máxima densidade de corrente específica aumentou significativamente de $456,42 \mathrm{~mA} / \mathrm{m}^{2}(1000 \Omega)$ para 564,28 $\mathrm{mA} / \mathrm{m}^{2}(560 \Omega)$ e posteriormente para $630,64 \mathrm{~mA} / \mathrm{m}^{2}(100 \Omega)$, desempenho semelhante aos obtidos por (Jung e Regan, 2011; Lyon et al., 2010). Contrariamente quando a $\mathrm{R}_{\text {ext }}$ de $47 \Omega$ foi aplicada ao sistema, a densidade de corrente específica decresce para $418,20 \mathrm{~mA} / \mathrm{m}^{2}$ para potenciais a baixo de $300 \mathrm{mV}$. Através da regressão linear foram determinadas as resistências internas $\left(\mathrm{R}_{\text {int }}\right)$ referentes a cada uma das resistências em estudo, conforme apresentado na 
Tabela 1. Na tabela pode-se observar que as $R_{\text {ext }}$ mínima e máxima (1000 e $47 \Omega$ ) em estudo apresentaram maiores valores para a $R_{\text {int }}$ frente às intermediárias $(560$ e $100 \Omega)$.

Tabela 1 - Propriedades eletroquímicas de uma CCM nas diferentes condições de $\mathrm{R}_{\text {ext }}$

\begin{tabular}{cccc}
\hline $\mathrm{R}_{\mathrm{ext}}{ }^{\mathrm{a}}(\Omega)$ & $\mathrm{R}_{\mathrm{int}}{ }^{\mathrm{b}}(\Omega)$ & $\mathrm{R}_{\mathrm{ohm}}{ }^{\mathrm{c}}(\Omega)$ & $\mathrm{R}_{\mathrm{ct}}{ }^{\mathrm{d}}(\Omega)$ \\
\hline 1000 & 60,24 & 2,05 & 189,13 \\
560 & 35,02 & 2,48 & 54,50 \\
100 & 44,63 & 2,28 & 42,09 \\
47 & 61,97 & 2,09 & 40,91 \\
\hline
\end{tabular}

aResistência externa.

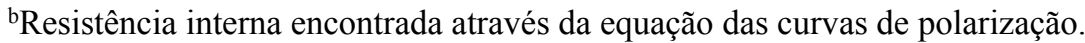

'Resistência ôhmica obtida pela análise eletroquímica IES.

dResistência à transferência de carga obtida através da análise eletroquímica IES.

A Figura 2(b) refere-se ao comportamento eletroquímico obtido por meio da Espectroscopia de Impedância. Através da regressão não linear de segundo grau foram obtidas as $R_{\mathrm{ohm}}$ e a $R_{\mathrm{ct}}$. $A \mathrm{R}_{\mathrm{ohm}}$ não apresentou grandes alterações frente à variação das resistências em estudo, pois esta associada a parâmetros que não foram alterados durante o experimento, como membrana trocadora de prótons e a solução eletrolítica (Sekar e Ramasamy 2013). Já a $\mathrm{R}_{\mathrm{ct}}$ decresceu conforme a $\mathrm{R}_{\mathrm{ext}}$ foi reduzida, certamente devido o estabelecimento do biofilme.

\section{CONCLUSÃO}

O presente trabalho avaliou a influência da resistência externa na produção de energia, na geração de potência e na redução das resistências internas do sistema, através de análises eletroquímicas. Sendo obtido uma máxima densidade de corrente de $27,72 \mathrm{~mA} / \mathrm{m}^{2}, 53,14$ $\mathrm{mA} / \mathrm{m}^{2}, 95,12 \mathrm{~mA} / \mathrm{m}^{2}$ e $425,01 \mathrm{~mA} / \mathrm{m}^{2}$ conforme a $\mathrm{R}_{\text {ext }}$, foi alterada de $1 \mathrm{k} \Omega$, para $560 \Omega, 100$ $\Omega$ e $47 \Omega$ respectivamente. O máximo potencial também aumentou conforme a variação crescente da resistência em estudo apresentando valores de $18,85 \mathrm{~mW} / \mathrm{m}^{2}(1 \mathrm{k} \Omega), 36,70(560$ $\Omega), 114,51 \mathrm{~mW} / \mathrm{m}^{2}(100 \Omega)$ e $208,25 \mathrm{~mW} / \mathrm{m}^{2}(47 \Omega)$, comportamento este esperado já que de acordo com as Equações 1 e 2, com a diminuição da $R_{\text {ext }}$ e mantendo-se a diferença de potencial constante, a máxima densidade de corrente aumenta e, consequentemente, o máximo potencial atingido também aumenta. Frente à redução das resistências internas do sistema, se pode afirmar que a $R_{\text {ct }}$ decresceu conforme a $R_{\text {ext }}$ foi alterada de $1 \mathrm{k} \Omega$ para $560 \Omega$, $100 \Omega$ e finalmente $47 \Omega$, esta resistência esta associada a formação do biofilme.

\section{REFERÊNCIAS}

AELTERMAN, P.; VERSICHELE, M.; MARZORATI, M.; BOON, N.; VERSTRAETE, W. Loading rate and external resistance control the electricity generation of microbial fuel cells with different three-dimensional anode, Bioresource Technology, v. 99, p. 8895-8902, 2008.

IEROPOULOS, IA, GREENMAN, J, MELHUISH, C, HART, J. Comparative study of three types of microbial fuel cell. Enzyme and Microbial Technology, v. 37, p. 238-45, 2005. 
JIANG, D.; LI, B. Granular activated carbon single-chamber microbial fuel cells (GACSCMFCs): A design suitable for large-scale wastewater treatment processes. J. Biochemical Engineering v. 47, p. 31-37, 2009.

JUNG, S.; REGAN, J. M. Influence of External Resistance on Electrogenesis, Methanogenesis, and Anode Prokaryotic Communities in Microbial Fuel Cells Applied and Environmental Microbiology, v. 77, n. 2, p. 564-571, 2011.

LIU H.; CHENG S.; LOGAN B. E. Production of Electricity from Acetate or Butyrate Using a Single-Chamber Microbial Fuel Cell Environmental Science \& Technology, v. 39, p. 658-662, 2005.

LOGAN, B. E.; HAMELERS, B.; ROZENDAL, R.; SCHRÖDER, U.; KELLER, J.; FREGUIA, S.; AELTERMAN, P.; VERSTRAETE, W.; RABAEY, K.. Microbial Fuel Cells: Methodology and Technology. Environmental Science \& Technology, v. 40, n. 17, p. 51815192, 2006.

LOGAN, B. E.; REGAN, J. M. Electricity-producing bacterial communities in microbial fuel cells Trends in Microbiology, v.14, n. 12, p. 512-518, 2006.

LYON, D. Y.; BURET, F.; VOGEL, T. M.; MONIER, J. M. Is resistance futile? Changing external resistance does not improve microbial fuel cell performance Bioelectrochemistry, v. 78, p. 2-7, 2010.

PANT, D.; BOGAERT, G.V.; DIELS, L.; VANBROEKHOVEN, K. Bioresource Technology v. 101, p. 1533-1543, 2010.

SCOTT K.; COTLARCIUC I.; HALL D.; LAKEMAN J. B.; BROWNING D. Power from marine sediment fuel cells: the influence of anode material. J. Applied Electrochemistry v. 38, p. 1313-1319, 2008.

SEKAR N.; R. P. RAMASAMY Electrochemical Impedance Spectroscopy for Microbial Fuel Cell Characterization, J. Microbial Biochemical \& Technology, p. 2-14, 2013.

TELEKEN, J. T. Modelagem Matemática da Geração de Corrente Elétrica em uma Célula Combustível Microbiana Inoculada com Micro-Organismos Marinhos, Florianópolis, 2013.

YAZDI, H. R.; CHRISTY, A. D.; CARVER, S. M.; YU Z.; B. DEHORITY, A.; TUOVINEN, O. H. Effect of external resistance on bacterial diversity and metabolism in cellulose-fed microbial fuel cells, Bioresource Technology, v. 102, p. 278-283, 2011. 